\title{
Mohammad Taqi Atāyi, Shahram Zāre. « Bam dar nimeh nokhost hezāreh yek pm: neshāneh haye az takvin qodrat dar Irān sharqi/ Bam in the First Half of the First Millennium B.C.: Archaeological Evidence for the State Formation in Eastern Iran »
}

\section{Rémy Boucharlat}

\section{OpenEdition}

\section{Édition électronique}

URL : http://journals.openedition.org/abstractairanica/46273

DOI : 10.4000/abstractairanica.46273

ISBN : 1961-960X

ISSN : 1961-960X

Éditeur :

CNRS (UMR 7528 Mondes iraniens et indiens), Éditions de l'IFRI

\section{Référence électronique}

Rémy Boucharlat, « Mohammad Taqi Atāyi, Shahram Zāre. « Bam dar nimeh nokhost hezāreh yek pm: neshāneh haye az takvin qodrat dar Irān sharqi/ Bam in the First Half of the First Millennium B.C. Archaeological Evidence for the State Formation in Eastern Iran » », Abstracta Iranica [En ligne], Volume 37-38-39 | 2018, document 81, mis en ligne le 30 décembre 2018, consulté le 02 octobre 2020. URL : http://journals.openedition.org/abstractairanica/46273; DOI : https://doi.org/10.4000/ abstractairanica.46273

Ce document a été généré automatiquement le 2 octobre 2020.

Tous droits réservés 


\section{Mohammad Taqi Atāyi, Shahram Zāre. «Bam dar nimeh nokhost} hezāreh yek pm: neshāneh haye az takvin qodrat dar Irān sharqi/ Bam in the First Half of the First Millennium B.C.: Archaeological
Evidence for the State Formation in
Eastern Iran $"$

Rémy Boucharlat

\section{RÉFÉRENCE}

Mohammad Taqi Atāyi, Shahram Zāre. « Bam dar nimeh nokhost hezāreh yek pm : neshāneh haye az takvin qodrat dar Irān sharqi/ Bam in the First Half of the First Millennium B.C.: Archaeological Evidence for the State Formation in Eastern Iran », Bāstānpazhūhi, 9, No. 18-19, 2016, p. 76-92 (en persan, English summary p. 4-5).

Les auteurs sont des archéologues très actifs dans l'exploration archéologique de l'oasis de Bam depuis le tremblement de terre de 2003. Depuis que ces recherches ont révélé des occupations successives insoupçonnées dès le quatrième millénaire, la place de Bam dans les entités politiques préislamiques est un sujet de débat. Les A discutent ici de Bam aux époques pré-achéménide et achéménide, proposant même de reconnaître pour Narmāshir, près de Bam le toponyme attesté à Bisutun, vieux-perse Paišiyāuvādā, élamite Naširma. Ils proposent de l'identifier avec un énorme site de 450 ha à $12 \mathrm{~km}$ au 
sud de Bam, qui est d'époque achéménide selon la céramique. Ils indiquent aussi des résultat des datations par radiocarbone sur la paille de briques crues prélevées dans la plateforme qui supporte la fameuse citadelle de Bam, qui est 820-620 av.n.è, et, pour les plus anciens murs de cette dernière, $\mathrm{V}^{\mathrm{e}}$-début $\mathrm{III}^{\mathrm{e}}$ siècle av.n.è. Souhaitons la publication rapide de plus amples données. En Annexe sont présentées les anciennes carrières de pierre de Kork, à l'est de Bam, dont les matériaux auraient été utilisés pour établir la plateforme portant la citadelle de Bam, selon des analyses pétrographiques.

\section{AUTEURS}

RÉMY BOUCHARLAT

UMR 5133 CNRS-Université de Lyon 